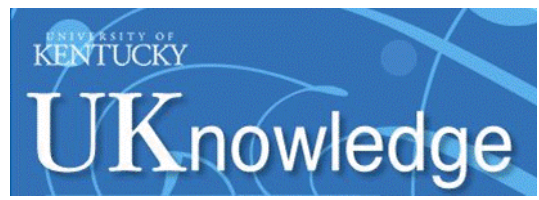

University of Kentucky

UKnowledge

Power and Energy Institute of Kentucky Faculty Publications

Power and Energy Institute of Kentucky

$10-2020$

\title{
Demand Response of HVACs in Large Residential Communities Based on Experimental Developments
}

\author{
Huangjie Gong \\ University of Kentucky, huangjie.gong@uky.edu \\ Evan S. Jones \\ University of Kentucky, SEvanJones@uky.edu \\ Rosemary E. Alden \\ University of Kentucky, rosemary.alden@uky.edu \\ Andrew G. Frye \\ Tennessee Valley Authority \\ Donald G. Colliver \\ University of Kentucky, dcolliver@uky.edu
}

See next page for additional authors

Follow this and additional works at: https://uknowledge.uky.edu/peik_facpub

Part of the Power and Energy Commons

Right click to open a feedback form in a new tab to let us know how this document benefits you.

\section{Repository Citation}

Gong, Huangjie; Jones, Evan S.; Alden, Rosemary E.; Frye, Andrew G.; Colliver, Donald G.; and Ionel, Dan M., "Demand Response of HVACs in Large Residential Communities Based on Experimental Developments" (2020). Power and Energy Institute of Kentucky Faculty Publications. 56.

https://uknowledge.uky.edu/peik_facpub/56

This Conference Proceeding is brought to you for free and open access by the Power and Energy Institute of Kentucky at UKnowledge. It has been accepted for inclusion in Power and Energy Institute of Kentucky Faculty Publications by an authorized administrator of UKnowledge. For more information, please contact UKnowledge@lsv.uky.edu. 


\title{
Demand Response of HVACs in Large Residential Communities Based on Experimental Developments
}

\author{
Digital Object Identifier (DOI) \\ https://doi.org/10.1109/ECCE44975.2020.9235465
}

\section{Notes/Citation Information}

Published in 2020 IEEE Energy Conversion Congress and Exposition (ECCE).

(C) 2020 IEEE Copyright Notice. "Personal use of this material is permitted. Permission from IEEE must be obtained for all other uses, in any current or future media, including reprinting/republishing this material for advertising or promotional purposes, creating new collective works, for resale or redistribution to servers or lists, or reuse of any copyrighted component of this work in other works."

The document available for download is the authors' manuscript version accepted for publication. The final published version is copyrighted by IEEE and available as: Gong H., Jones E. S., Alden R. E., Frye A. G., Colliver D., and lonel D. M., "Demand Response of HVACs in Large Residential Communities Based on Experimental Developments," Proceedings, IEEE Energy Conversion Congress and Exposition (ECCE), Detroit, MI, doi: 10.1109/ECCE44975.2020.9235465, pp.4545-4548, Oct 2020.

\section{Authors}

Huangjie Gong, Evan S. Jones, Rosemary E. Alden, Andrew G. Frye, Donald G. Colliver, and Dan M. Ionel 


\title{
Demand Response of HVACs in Large Residential Communities Based on Experimental Developments
}

\author{
Huangjie Gong, Evan S. Jones, Rosemary E. Alden, Andrew G. Frye ${ }^{1}$, Donald Colliver ${ }^{2}$, and Dan M. Ionel \\ SPARK Laboratory, ECE Department, University of Kentucky, Lexington, KY, USA \\ ${ }^{1}$ Tennessee Valley Authority, Knoxville, TN, USA \\ ${ }^{2}$ Biosystems and Ag Engineering Department, University of Kentucky, Lexington, KY, USA \\ huangjie.gong@uky.edu, sevanjones@uky.edu,rosemary.alden@uky.edu, agfrye@tva.gov, dcolliver@uky.edu, dan.ionel@ieee.org
}

\begin{abstract}
Heating, ventilation, and air-conditioning (HVAC) systems contribute the largest electricity usage for a residential community. Modeling of the HVAC systems facilitate the study of demand response (DR) at both the residential and the power system level. In this paper, the equivalent thermal model of a reference house was proposed. Parameters for the reference house were determined based on the systematic study of experimental data obtained from fully instrumented field demonstrators. The aggregated HVAC load was modeled based on the reference house while considering a realistic distribution of HVAC parameters derived from data that was provided by one of the largest smart grid field demonstrators in rural America. A sequential DR as part of a Virtual Power Plant (VPP) control was proposed to reduce both ramping rate and peak power at the aggregated level, while maintaining human comfort according to ASHRAE standard.

Index Terms-Heating, ventilation, and air-conditioning (HVAC), Home Energy Management (HEM), Demand Response (DR), Thermal Model, Aggregated, Virtual Power Plant (VPP), Smart Home, Smart Grids.
\end{abstract}

\section{INTRODUCTION}

For typical residences, heating, ventilation, and airconditioning (HVAC) systems use the highest percentage of energy [1]. They dominate the house energy usage and contribute the most to the peak power demand at the aggregated level. To accommodate large fluctuations in demand over the course of a day, expensive infrastructure must be installed to meet the maximum demand. In order to minimize investment, optimal control may be employed. This leads to extra cost and need for optimal control to reduce the peak power.

The thermal inertia of a house may be employed to turn off HVAC systems for a short time without affecting human comfort [2]. Price-based demand response (DR) schemes encourage house owners to turn off their HVAC when electricity charge rates are high. Studies have found that generation capacity in Houston may be reduced by $459 \mathrm{MW}$ if, for example, residential consumers are rewarded \$10/month [3]. To ensure adequate human comfort, HVAC control has to follow Standard 55 of the American Society of Heating, Refrigerating and Air-Conditioning Engineers (ASHRAE), in terms of external and internal temperature, relative humidity, individual metabolic rate, etc. [4].

In this paper, the thermal model of a reference house is proposed and equivalent parameters are derived from experimental data provided by a robotic house project conducted by the Tennessee Valley Authority (TVA) on a field demonstrator in Knox County, TN. The equivalent thermal resistance of the reference house was analyzed. The aggregated HVAC power for 10,000 houses within a community that may participate in a DR program was modeled based on experimental data from the Smart Energy Technologies (SET) project from Glasgow, $\mathrm{KY}$, one of the largest smart grid demonstrators in the rural US [5]. The human comfort standards according to ASHRAE were taken into consideration. The control of virtual power plant (VPP) through DR of HVAC systems was experimentally implemented and results show that both ramping rate and peak power were reduced at the power system level.

\section{Experimental Results and Derivation of House THERMAl Model PARAMETERS}

Beginning in 2008, TVA funded and managed a robotic house project with technical support from the Oak Ridge National Laboratory (ORNL). Robotic houses were constructed in a suburb of Knox County, TN in which the habitation of a family was physically simulated (Fig. 1). This project developed an analytical base for the energy optimization and new technology implementation at individual house level. A different initiative, the Smart Energy Technologies (SET) project based in Glasgow, KY, provided a testbed for the optimization of power flow at the community level.

In the TVA robotic house, energy usage for different components, including the HVAC, was measured on an hourly basis. The data was used to derive the equivalent model that represents a typical residence, which was defined by parameters such as thermal envelope area, thermal resistance, thermal capacitance, and heat transfer rate.

The thermal envelope area is the only independent variable for the equivalent model. Other parameters for the equivalent thermal model were calculated using the thermal envelope area and coefficients, as follows:

$$
R=\frac{c_{R}}{A_{r}}, C=c_{C} \cdot A_{r}, P_{H}=c_{P} \cdot A_{r},
$$




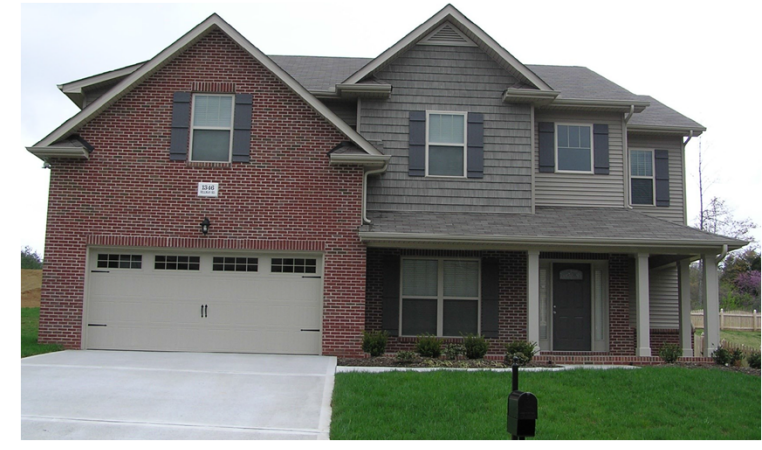

(a)

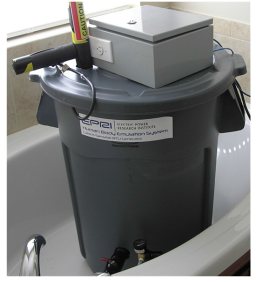

(b)

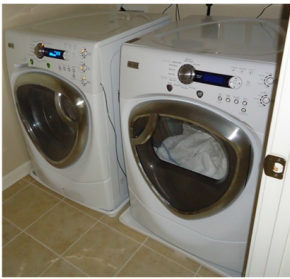

(c)

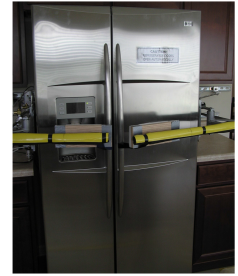

(d)
Fig. 1. The reference house (a). TVA robotic devices are controlled by computer programs to mimic realistic human behavior. Also shown is a shower emulator (b), a dryer and a washer (c), and a refrigerator with programmed arms (d) that activate according to automatic schedules.

Table I

PARAMETERS FOR THE THERMAL MODEL OF THE REFERENCE HOUSE

\begin{tabular}{ll}
\hline Parameter & Value \\
\hline Thermal envelope area $A_{r}$ & $354 \mathrm{~m}^{2}$ \\
Coefficient of thermal resistance $c_{R}$ & $350{ }^{\circ} \mathrm{C} \cdot \mathrm{m}^{2} / \mathrm{kW}$ \\
Coefficient of thermal capacitance $c_{C}$ & $0.011 \mathrm{kWh} /\left({ }^{\circ} \mathrm{C} \cdot \mathrm{m}^{2}\right)$ \\
Coefficient of heat transfer rate $c_{P}$ & $0.040 \mathrm{~kW} / \mathrm{m}^{2}$ \\
\hline
\end{tabular}

where $R$, is the thermal resistance; $\mathrm{C}$, the thermal capacitance; and $P_{H}$, heat transfer rate.

The heat transfer function of the residential thermal model is described as follows,

$$
C \frac{\mathrm{d} \theta_{I}(t)}{\mathrm{d} t}=\frac{1}{R}\left[\theta_{O}(t)-\theta_{I}(t)\right]-S(t) \cdot P_{H},
$$

where $\theta_{I}$ is the indoor temperature; $\theta_{O}$, the outdoor temperature; $S$, the On/Off status of HVAC, defined as:

$$
S(t)= \begin{cases}0, & \text { if } S(t-1)=1 \& \theta_{I}(t) \leq \theta_{L}(t) \\ 1, & \text { if } S(t-1)=0 \& \theta_{I}(t) \geq \theta_{H}(t) \\ S(t-1), & \text { otherwise, }\end{cases}
$$

where $\theta_{L}$ and $\theta_{H}$ are the lower and upper band of the thermostat setting point, of $70 \mathrm{~F}$ and $74 \mathrm{~F}$, respectively.

The robotic house provides data with a time-step of $1 \mathrm{~h}$. The thermal resistance $R$ was calculated assuming that the indoor temperature remained the same for every two consecutive hours, or $\mathrm{d} \theta_{\mathrm{I}}(\mathrm{t})=0$ in (2). Only hourly data for 12:00-16:00 of each day in July was used to estimate the coefficient of thermal resistance $c_{R}$, assuming that the HVAC would be working, or $S(t)=1$ in (2). The calculated coefficients of the equivalent

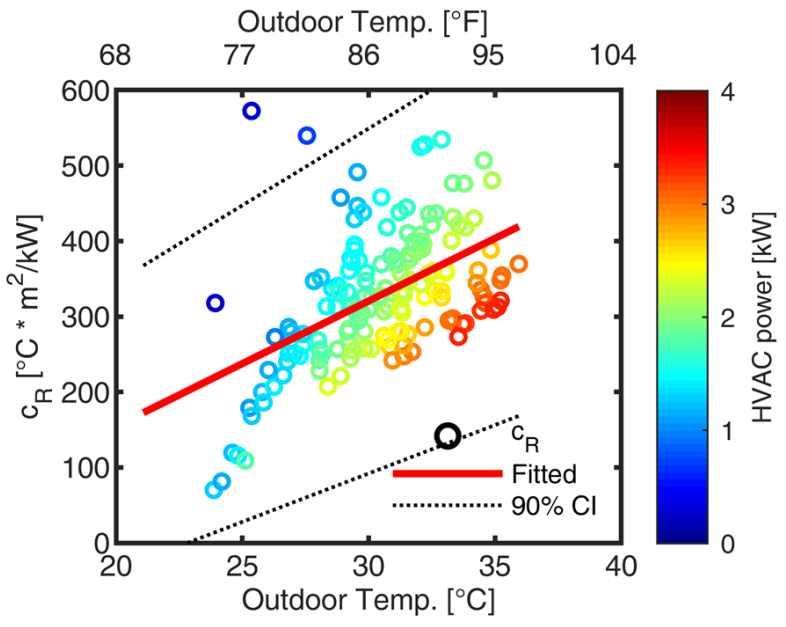

Fig. 2. Analysis of the $c_{R}$ equivalent thermal resistance coefficient for the reference house. Data corresponds to 5 hours during the time interval of direct interest for DR studies of each day in July 2010. Data was fitted with a $90 \%$ confidence interval, and only 2 points were outside the bounds.

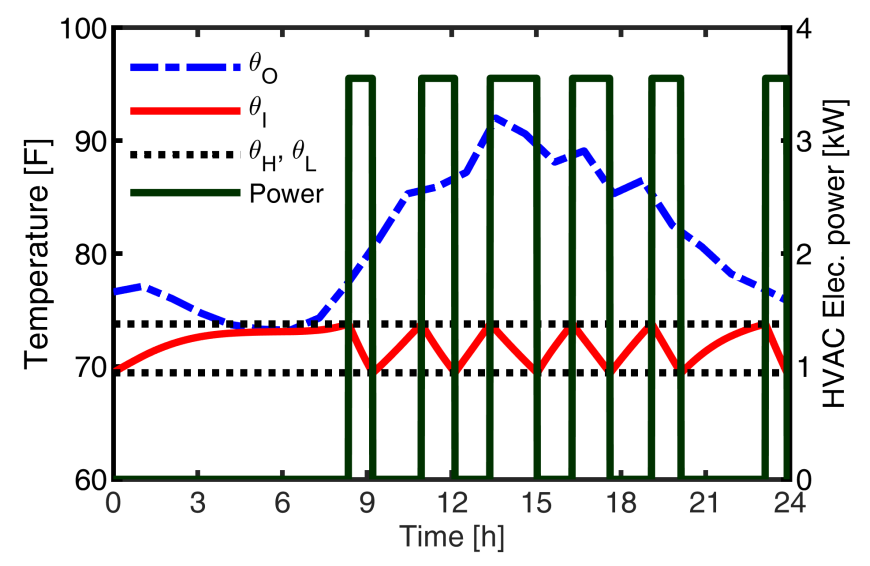

Fig. 3. The daily simulation example of the HVAC system for the reference house. With a cooling capacity of 4 tons and a SEER of 13.5, the HVAC has approximately $3.6 \mathrm{~kW}$ of constant electric power during operation.

resistance based on the robotic house data is shown in Fig. 2. The solar heat gain as well as the latent and appliance heat gains were lumped together in the thermal resistance term.

The HVAC system for the reference house was modeled with fixed parameters (Table I). The envelope area was calculated according to the floor plan. The coefficient of thermal resistance $c_{R}$ was selected according to the data analysis shown in Fig. 2. The $c_{C}$ and $c_{P}$ were adjusted based on the envelope area and recommended values [6]. With a cooling capacity of 4 tons and a Seasonal Energy Efficiency Ratio (SEER) of 13.5, the HVAC system had a constant input electrical power of approximately $3.6 \mathrm{~kW}$ when it was ON (Fig. 3).

\section{Modeling of Aggregated HVAC LoAd}

The aggregated HVAC system loads were modeled by (2) and (3) according to their own sets of parameters. The 


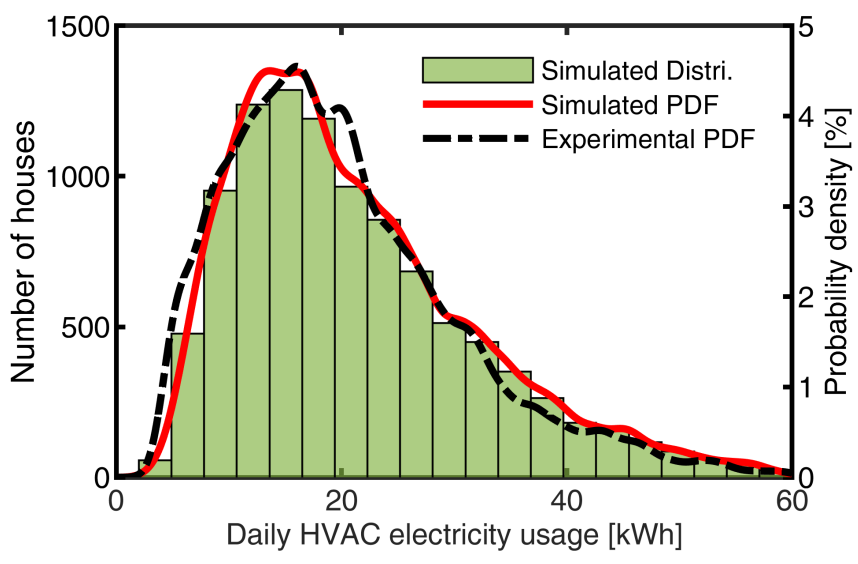

Fig. 4. The distribution of daily HVAC electricity usage on a typical summer day for 10,000 houses in a large community case study. The experimental probability density function (PDF) is estimated based on daily residential electricity usage from the SET project on the same day.

aggregated HVAC power was calculated as:

$$
P_{A}(t)=\frac{1}{S E E R} \sum_{i=1}^{N} S^{i}(t) P_{H}^{i},
$$

where $\mathrm{N}$ is the total number of studied HVACs; $P_{H}^{i}$ the heat transfer rate of house $i$ in $\mathrm{btu} / \mathrm{h}$.

In this study, the $A_{R}$ and $c_{R}$ for the 10,000 HVACs were subject to normal distribution, and the standard deviations were selected such that simulated data would have a similar probability density function (PDF) for daily HVAC electricity usage when compared to the experimental data (Fig. 4). The distributions were noted as $\boldsymbol{A}_{\boldsymbol{R}} \sim \mathcal{N}\left(354,200^{2}\right)$ and $\boldsymbol{c}_{\boldsymbol{R}} \sim \mathcal{N}\left(350,280^{2}\right)$. The upper limit setting points of the 10,000 houses that participate were randomly generated, noted as uniform distribution $\mathcal{U}(74 F, 78 F)$. The initial indoor temperatures were subject to uniform distribution $\mathcal{U}\left(\theta_{L}, \theta_{H}\right)$. The values for the coefficients $c_{C}$ and $c_{P}$ for all the 10,000 houses were set to the same, respectively (Table I).

The simulation results of the working status for the 10,000 participating HVACs are shown in Fig. 5. In the morning, even though the outdoor temperature is higher than the setting point, not every HVAC turned on due to the thermal inertia of the house. Around 9:00, many HVACs started to turn on as the outdoor temperature increased quickly.

The simulated HVAC systems were grouped according to their daily electricity usage, and the distribution is shown in Fig. 4. The simulated HVAC systems within the large community that participate in the DR study had a similar distribution as compared with the experimental data.

\section{The Optimal Control of the HVAC Systems}

Two objectives were considered for VPP controls:

$$
\begin{aligned}
& O b j 1: \operatorname{Min} \max \left(P_{A}(t)\right), \\
& O b j 2: \operatorname{Min} \max \left(\frac{P_{A}(t+\Delta t)-P_{A}(t)}{\Delta t}\right),
\end{aligned}
$$

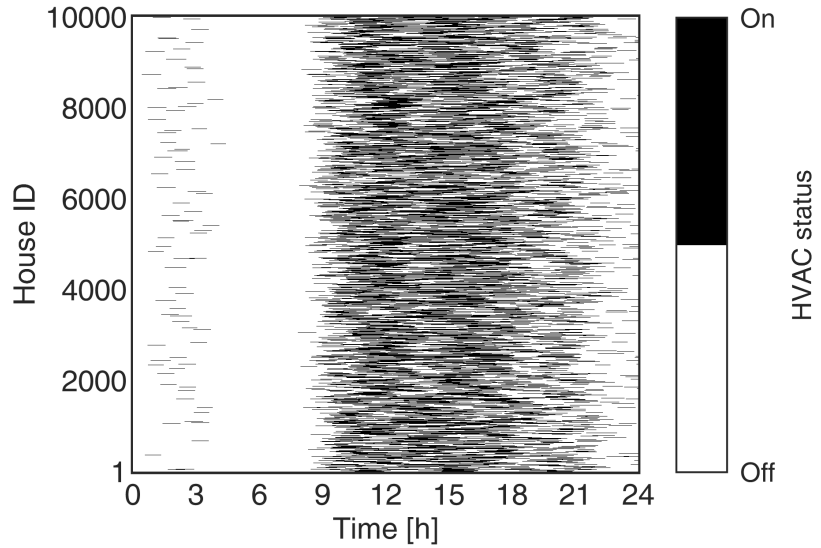

Fig. 5. The working status for the simulation of 10,000 participating HVAC systems without DR. Most of the HVAC systems started turning on around 9:00 due to the increase in outdoor temperature.

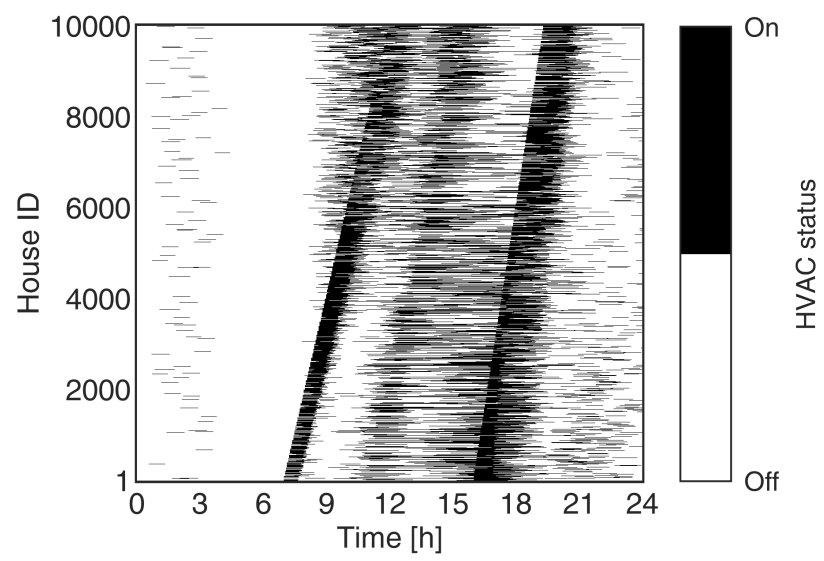

Fig. 6. The working status for the simulation of 10,000 HVAC systems in a DR study with centralized controls. HVAC systems were turned on/off in a sequential way, reducing the ramping rate and the peak load.

where Obj1 aims to reduce the peak demand and Obj2 targets the reduction of the maximum ramping rate at the distribution system level.

In the DR case study, the 10,000 simulated houses were divided into 100 groups. The working status of HVACs is shown in Fig. 6. The HVACs were turned on and off in a sequential way in order to avoid a sudden change of the aggregated power. The outdoor temperature and average indoor temperatures of all the houses are shown in Fig. 7.

The proposed sequential DR control strategy is exemplified on a study that successfully results in a very large reduction of the peak power at the critical time of 15:00, by allowing temporarily high temperatures inside the participating homes (Figs. 7 and 8). The selection of the maximum allowed indoor temperature, which is $80^{\circ} \mathrm{F}$ for the illustrated example, is based on a combination of human comfort regulations, as per ASHRAE Standard 55-2017, and user behavior preferences, as expressed through enrollment in different DR schemes that trade comfort controls versus unitary electricity cost [4]. It 


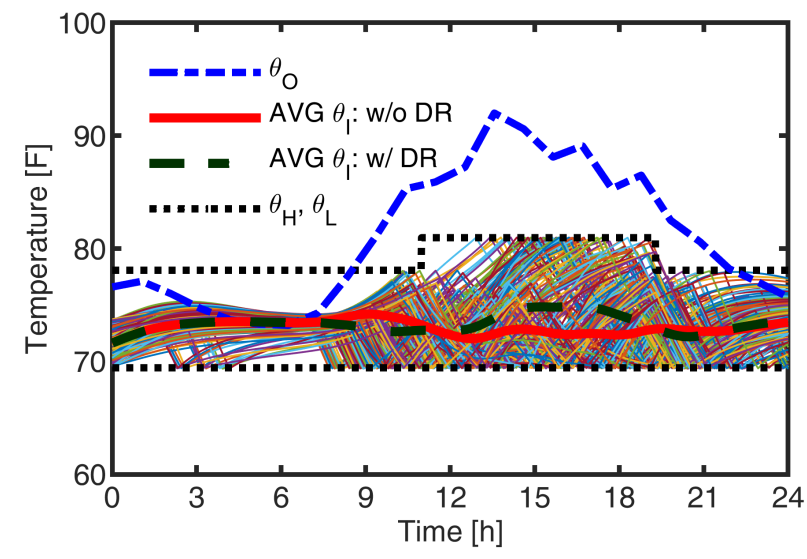

Fig. 7. The outdoor temperature and average indoor temperatures of the 10,000 simulated HVAC systems. For the DR program, indoor temperature was allowed to be higher but still acceptable according to ASHRAE standard.

should be noted that the average temperature for all homes does not exceed $75^{\circ} \mathrm{F}$ at any time and that only very few homes, which selected a minimum electricity cost DR program option, reach the $80^{\circ} \mathrm{F}$ maximum temperature after 17:00, and even then, only for a very short duration of time.

The aggregated HVAC power from Fig. 8 shows that under normal operation without DR controls, the ramping rate around 8:00 was fast increased due to the rise of outdoor temperature. The ramping rate was reduced by the precooling. The total daily HVAC electricity usage was reduced from 213MWh to 203MWh. As a consequence of indoor temperature recovery, the peak power period for the w/ DR case was shifted to a later time. At the critical period of around 15:00, the power was reduced from the previous peak of $21.3 \mathrm{MW}$ to $16.6 \mathrm{MW}$.

\section{CONClusion}

The model proposed in the paper for residential buildings with HVAC systems employs an equivalent thermal resistance, which was determined based on a systematic study that employed a large number of electric power measurements on summer days with typical environmental and indoor ranges of temperatures. The house utilized for modeling was a fully instrumented field demonstrator that is representative of regional communities in the very large service area of TVA. The example building model and its equivalent circuit parameter values provide a useful reference that is suitable for Virtual Power Plant (VPP) and Demand Response (DR) studies of HVAC systems in large residential electric power distribution systems.

Another contribution of the paper consists of an aggregation technique for large communities that is based on the reference building and employs a realistic distribution of HVAC parameters and loads, which were derived with data from one of the largest smart grid field demonstrators in rural America. The resultant aggregated model and a VPP sequential control scheme for groups of HVAC systems has been illustrated

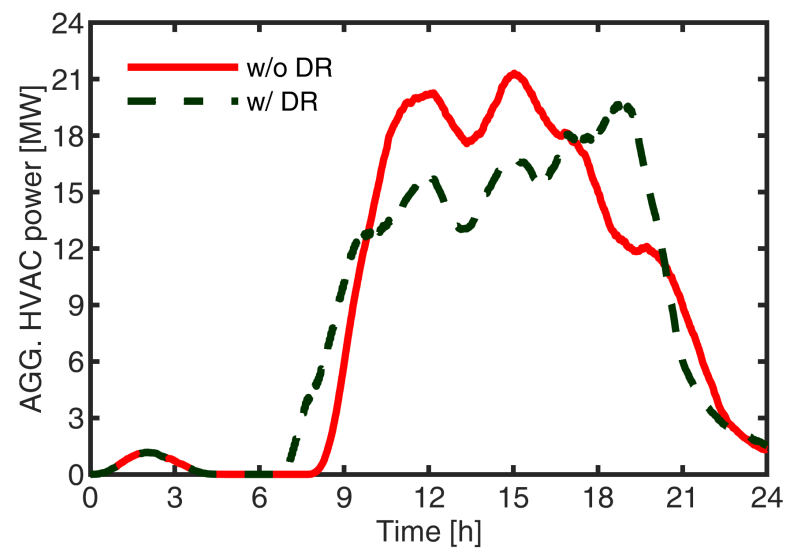

Fig. 8. Simulation results of aggregated HVAC power for the 10,000 houses studied. The DR was applied throughout the entire day in expectation of a peak load around 15:00. At the critical hour, the peak power was reduced by approximately $20 \%$. The total daily energy usage was reduced by approximately $4 \%$. Ramping rate in the morning was reduced by precooling.

through a theoretical study of 10,000 homes participating in a DR program with different consumer options.

The results show that, under the conditions and assumptions considered for the community on a very hot summer day, the load profile can be shifted, such that the peak power at the anticipated critical time is reduced by approximately $20 \%$ and the daily energy use is reduced by approximately 4\%. The example improved operation is achieved through advanced VPP controls and by temporarily allowing higher indoor temperatures up to values that are still considered acceptable for typical preferences and standard regulations of human comfort.

\section{ACKNOWLEDGMENT}

The support of the Tennessee Valley Authority (TVA) and of University of Kentucky, the L. Stanley Pigman endowment is gratefully acknowledged.

\section{REFERENCES}

[1] "Residential energy consumption survey (RECS)," https://www.eia.gov/ consumption/residential/index.php, accessed: 2020-06-29.

[2] A. Mammoli, P. Vorobieff, H. Barsun, R. Burnett, and D. Fisher, "Energetic, economic and environmental performance of a solar-thermalassisted hvac system," Energy and Buildings, vol. 42, no. 9, pp. 1524$1535,2010$.

[3] Q. Shi, C.-F. Chen, A. Mammoli, and F. Li, "Estimating the profile of incentive-based demand response (IBDR) by integrating technical models and social-behavioral factors," IEEE Transactions on Smart Grid, vol. 11, no. 1, pp. 171-183, 2019.

[4] American National Standards Institute and American Society of Heating, Refrigerating and Air-Conditioning Engineers, ANSI/ASHRAE Standard 55-2017 Thermal environmental conditions for human occupancy. American Society of Heating, Refrigerating and Air-Conditioning Engineers (ASHRAE), 2017.

[5] H. Gong, V. Rallabandi, M. L. McIntyre, and D. M. Ionel, "On the optimal energy controls for large scale residential communities including smart homes," in 2019 IEEE Energy Conversion Congress and Exposition (ECCE), Baltimore, MD, USA, 2019, pp. 503-507.

[6] D. S. Callaway, "Tapping the energy storage potential in electric loads to deliver load following and regulation, with application to wind energy," Energy Conversion and Management, vol. 50, no. 5, pp. 1389-1400, 2009. 